\title{
Review
}

\section{Cerebrospinal fluid as a medium of liquid biopsy in the management of patients with non-small-cell lung cancer having central nervous system metastasis}

\author{
Chi-Lu Chiang ${ }^{1,2,3}$, Hsu-Ching Huang ${ }^{1,2}$, Yung-Hung Luo ${ }^{1,2,3}$, Chao-Hua Chiu ${ }^{1,2, *}$ \\ ${ }^{1}$ Department of Chest Medicine, Taipei Veterans General Hospital, 112 Taipei, Taiwan, ${ }^{2}$ School of Medicine, National \\ Yang Ming Chiao Tung University, 112 Taipei, Taiwan, ${ }^{3}$ Institute of Clinical Medicine, National Yang Ming Chiao Tung \\ University, 112 Taipei, Taiwan
}

\section{TABLE OF CONTENTS}

\author{
1. Abstract \\ 2. Introduction \\ 3. CSF as a medium of liquid biopsy in lung cancer \\ 3.1 Circulating tumor cells \\ 3.2 Cell-free tumor DNA \\ 3.3 EVs and RNA \\ 4. Summary and perspective \\ 5. Author contributions \\ 6. Ethics approval and consent to participate \\ 7. Acknowledgment \\ 8. Funding \\ 9. Conflict of interest \\ 10. References
}

\section{Abstract}

The molecular profiling of tumors is fundamental in the management of advanced non-small-cell lung cancer (NSCLC). A tissue specimen obtained from biopsy is needed for diagnosis and mutation analysis. However, this may not be feasible for some metastatic sites, such as central nervous system (CNS) lesions, particularly for repeated biopsy. Liquid biopsy with plasma is an emerging tool for molecular testing and could be a surrogate method if tissue cannot be obtained. However, the use of plasma is limited for the detection of mutations arising from intracranial lesions. Cerebrospinal fluid (CSF) was recently demonstrated to be an alternative material for genetic testing in patients with NSCLC having CNS metastasis. In this review, we discuss recent advancement in the use of CSF as a medium of liquid biopsy in patients with NSCLC.

\section{Introduction}

Central nervous system (CNS) metastases are common in patients with lung cancer and are associated with significant morbidity and mortality. The incidence

is approximately $25 \%-30 \%$ in patients with non-small-cell lung cancer (NSCLC), particularly in oncogene-addicted NSCLC, and $\geq 45 \%$ of patients undergoing targeted therapy have CNS involvement within 3 years [1, 2]. Previous studies have revealed that the presence of driver oncogenes, such as epidermal growth factor receptor (EGFR) mutation, are risk factors for brain metastasis [3-5]. Furthermore, isolated CNS metastasis progression can occur due to poor drug penetration into the cerebrospinal fluid (CSF) [6]. Moreover, CNS metastasis may have an evolutionary pattern that is distinct from that of extracranial metastasis. Through the whole exome sequencing of paired primary and metastatic pulmonary adenocarcinoma tumors, Jiang et al. [7] discovered that brain metastatic tumors had a more varied mutational landscape than did liver metastatic lesions in comparison with their primary tumors. Brain metastasis is likely to have a parallel evolutionary model. Tumor driver gene-associated signaling pathways are crucial for promoting tumor cell survival, invasion, and colonization in the CNS [8]. These findings elucidate the biology of CNS metastasis in lung cancer and may lead to the development of a novel approach to preventing CNS metastasis. 
Leptomeningeal metastasis (LM) is a late and lethal complication of various solid tumors, defined as the seeding of tumor cells into the CSF and leptomeninges [9]. LM incidence in patients with NSCLC is approximately $3 \%-5 \%$ and reaches up to $9.4 \%$ in patients with EGFR mutation $[10,11]$. The prognosis of patients with NSCLC having LM is poor, with a median survival of $<1$ year despite advances in treatment [12]. LM diagnosis is challenging and is achieved through clinical evaluation, CSF cytological examination, and neuroimaging. Although an established diagnostic algorithm exists, novel approaches are needed for improving diagnosis, stratifying risk and monitoring treatment in this patient group [13, 14].

Liquid biopsy with plasma is an emerging tool for molecular testing and could be a surrogate method if tissue cannot be obtained [15]. However, the use of plasma cell-free DNA may be limited for the detection of mutations arising from intracranial lesions and may have limited performance in patients with isolated CNS progression $[16,17]$. CSF, by contrast, circulates throughout the CNS and may provide a window to investigating intracranial lesions. The CNS includes two anatomic compartments, namely the brain parenchyma and leptomeningeal space. The blood-brain barrier and blood-CSF barrier are the two barrier systems for each compartment [18]. CSF enters the parenchyma along paravascular spaces that surround penetrating arteries and the brain interstitial fluid is cleared along paravenous drainage pathways [19]. Because these two compartments are not anatomically isolated, CSF-based liquid biopsy of CNS metastatic lesions could be investigated in clinical practice. Research indicates that CSF harbors clinically relevant genomic alterations in patients with CNS malignancies and could be considered for liquid biopsies to monitor tumor evolution in the CNS [20]. Different tumor components in the CSF are subjects to be analyzed, such as circulating tumor cells (CTCs), cell-free tumor DNA (ctDNA), extracellular vesicles (EVs), and RNA. In this article, we reviewed relevant Englishlanguage journals articles indexed in PubMed (using the search terms "CSF", "CTCs", “ctDNA", "RNA", "EVs" and "lung cancer”) from January 2000 to August 2021.

\section{CSF as a medium of liquid biopsy in lung cancer}

\subsection{Circulating tumor cells}

The presence of malignant cells in CSF remains the gold standard for diagnosing LM; however, the sensitivity of a single lumbar puncture is low and repeated sampling is often needed [12, 21]. Some technical issues such as inadequate CSF volume for the analysis or delayed processing may lead to false negative results [22]. Recently, novel assays have been developed to detect and quantify CTCs in CSF. CellSearch assay and immunoflow cytology methods have been the two most common techniques applied.
The CellSearch platform uses epithelial cell adhesion molecule (EpCAM) antibody-conjugated ferroparticles and an immunomagnetic selection system to capture tumor cells in CSF. CTCs are defined as epithelial staining positive cells which lack CD45 expression [18]. Conversely, the immunoflow cytometry technique uses fluorescently labeled antibodies against membrane-bound proteins of epithelial tumor cells, such as EpCAM. Subsequently, CTC enumeration is performed using the fluorescenceactivated cell sorting system. Furthermore, leukocytes and other hematopoietic cells are labeled to select CTCs [18]. To date, many studies have used these two assays to detect CTCs in the CSF of patients with solid tumors and LM and have mainly focused on patients with NSCLC (Table 1, Ref. [23-32]). Overall, sensitivity is significantly higher with CTCs (75\%-100\%) than with conventional cytology (44.4\%-65.3\%) [23-31, 33]. Moreover, the CTC percentage in CSF is correlated with overall survival [25, 32]. However, the application of these assays in clinical practices has some limitations. Previous studies have focused only on patients with LM, and the use of CTCs in patients with parenchymal-only CNS metastasis remains unknown. Furthermore, the difference in experimental procedures and cutoff values between studies entail a need to conduct large prospective trials for validation. CTCs may have low EpCAM expression due to the epithelial-tomesenchymal transition [34]. This leads to the underestimation of the CTC number, and key subpopulations may be overlooked.

In addition to the identification and quantitation of CTCs in CSF, researchers have attempted to analyze the genetic alteration of CTCs in CSF. Using next-generation sequencing (NGS), Jiang et al. [28] observed that the genetic profiles of CSF CTCs were highly concordant with primary tumors $(17 / 19,89.5 \%)$. In addition to other resistant mutations, the EGFR exon 20 p.T790M resistant mutation was identified in $7.1 \%$ of patients. Furthermore, van Bussel et al. [31] exhibited a high EGFR mutation detection rate $(4 / 5,80 \%)$ in CTCs from CSF of patients with EGFRmutant NSCLC patients. Ruan et al. [35] further sequenced the CSF CTCs from patients with lung adenocarcinoma into a single cell level and found that metastatic-CTCs were enriched for metabolic and cell-adhesion pathways. Furthermore, interpatient and intrapatient heterogenicities were observed. These novel techniques break new ground in the diagnosis and treatment of LM in patients with NSCLC.

\subsection{Cell-free tumor DNA}

The constituents of cell-free DNA extracted from plasma are mostly the germline DNA from white blood cells, which make ctDNA analysis challenging due to high background noise. On the other hand, cell-free DNA extracted from CSF of patients with cancer is thought to be enriched for ctDNA due to the significantly lower number of normal cells in CSF compared with that in blood. Using 
Table 1. Studies on CTCs in CSF of patients with lung cancer with brain metastasis.

\begin{tabular}{|c|c|c|c|c|c|}
\hline Study & Platform for sequencing & Condition of patient population & Number (Total/LC) & Main finding & Molecular application \\
\hline Subirá et al., 2012 [23] & $\begin{array}{l}\text { Flow cytometry } \\
\text { immunophenotyping }\end{array}$ & Epithelial-cell solid tumors with suspected LM & $78 / 23$ & $\begin{array}{c}\text { CTC exhibited higher sensitivity compared with } \\
\text { cytology ( } 75.5 \% \text { vs. } 65.3 \%)\end{array}$ & NA \\
\hline Nayak et al., 2013 [24] & CellSearch assay & Solid tumors with suspected LM & $51 / 21$ & $\begin{array}{c}\text { CTC showed exhibited sensitivity compared with } \\
\text { cytology ( } 100 \% \text { vs. } 66.7 \%)\end{array}$ & NA \\
\hline Subirá et al., 2015 [25] & $\begin{array}{l}\text { Flow cytometry } \\
\text { immunophenotyping }\end{array}$ & Epithelial-cell solid tumors with LM & $144 / 35$ & $\begin{array}{c}\text { CTC exhibited higher sensitivity compared with } \\
\text { cytology (79.8\% vs. 50\%) } \\
\text { The percentage of CSF EpCAM+ cells predicted } \\
\text { overall survival }\end{array}$ & NA \\
\hline Tu et al., 2015 [26] & CellSearch assay & LC with MRI confirmed LM & $18 / 18$ & $\begin{array}{c}\text { CTC exhibited higher sensitivity compared with } \\
\text { cytology ( } 77.8 \% \text { vs. } 44.4 \%)\end{array}$ & NA \\
\hline $\begin{array}{l}\text { Milojkovic Kerklaan et al., } \\
2016 \text { [27] }\end{array}$ & EpCAM-based flow cytometry & $\begin{array}{l}\text { Epithelial-cell solid tumors with clinical suspicion of } \\
\text { LM but a negative or inconclusive MRI }\end{array}$ & $29 / 8$ & $\begin{array}{l}\text { CTC exhibited higher sensitivity compared with } \\
\text { cytology (100\% vs. } 61 \%)\end{array}$ & NA \\
\hline Lv, et al., 2016 [33] & $\begin{array}{c}\text { Immunofluorescence in situ } \\
\text { hybridization }\end{array}$ & LC with LM & $16 / 16$ & Sensitivity of CTC: $75 \%$ & NA \\
\hline Jiang et al., 2017 [28] & $\begin{array}{c}\text { CellSearch assay and } \\
\text { next-generation sequencing }\end{array}$ & LC with suspected LM & $21 / 21$ & $\begin{array}{c}\text { CTC showed exhibited sensitivity compared with } \\
\text { cytology ( } 95.2 \% \text { vs. } 57.1 \%)\end{array}$ & $\begin{array}{c}\text { Concordant rate with primary } \\
\text { tumor: } 89.5 \% \\
1 / 14 \text { had EGFR p.T790M } \\
\text { mutations }\end{array}$ \\
\hline Lin et al., 2017 [29] & CellSearch assay & Epithelial-cell tumors with suspected LM & $95 / 31$ & $\begin{array}{l}\text { Sensitivity of CTC: } 93 \% \\
\text { Cut-off for CTC positivity: } 1 \mathrm{CTC} / \mathrm{mL}\end{array}$ & NA \\
\hline Nevel et al., 2020 [32] & CellSearch assay & LC with LM & $16 / 16$ & CTC $(\geq 50 / \mathrm{mL})$ predicted overall survival & NA \\
\hline Torre M, et al., 2020 [30] & CellSearch assay & Solid tumor with suspected LM & $20 / 4$ & $\begin{array}{c}\text { Sensitivity of CTC: } 88.9 \% \\
\text { Cutoff for CTC positivity: } 1 \mathrm{CTC} / \mathrm{mL}\end{array}$ & NA \\
\hline Van Bussel, et al. 2020 [31] & EpCAM-based flow cytometry & NSCLC with suspected LM & $81 / 81$ & $\begin{array}{c}\text { Sensitivity of CTC: } 88.9 \% \\
\text { Cutoff for CTC positivity: } 0.9 \mathrm{CTC} / \mathrm{mL}\end{array}$ & 4/5 had EGFR mutation in CTC \\
\hline
\end{tabular}

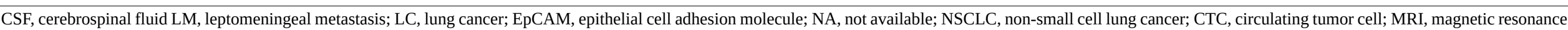
imaging; $E G F R$, epidermal growth factor receptor. 
mutation allele-specific amplification, Swinkels et al. [36] first identified KRAS mutation in CSF of two patients with NSCLC with LM. Subsequent studies, using either polymerase chain reaction (PCR) or NGS, have demonstrated that CSF ctDNA is a feasible material for mutation detection, particularly in patients with LM, with a detection rate as high as $100 \%$ [17, 37-50]. Published studies on ctDNA in CSF of patients with NSCLC with CNS metastasis are summarized in Table 2 (Ref. [17, 20, 36-53]). Most studies have focused on patients with EGFR-mutant NSCLC with LM due to the relatively high number of these patients [10]. Li et al. [39] eported that among patients with EGFR mutant NSCLC patients with LM, the ctDNA of CSF supernatant had a unique genetic profile and high allele fractions compared with CSF pellets or plasma. Furthermore, in patients with brain metastasis, the detection of ctDNA mutation is higher in CSF than in plasma, ranging from $50 \%$ to $63 \%$ [16, 20, 51]. These results reveal that CSF ctDNA is a feasible material for mutation testing.

Acquired resistance at disease progression is often inevitable after the use targeted therapies. Tumor rebiopsy is required to obtain information regarding histologic or genetic changes. For patients with LM, tissue rebiopsy is not feasible, and CSF ctDNA could provide useful information for subsequent treatment in this scenario. EGFR exon 20 p.T790M mutation, which is the most common resistant mechanism after first- or second- generation EGFRtyrosine kinase inhibitor (TKI), has an incidence rate of approximately 55\%-64\% $[54,55]$. Despite the difference in the testing method used, the percentage of EGFR exon 20 p.T790M mutation was relatively low in CSF ctDNA, ranging from $0 \%$ to $50 \%$ [20, 38-40, 42, 43, 48, 51, 52]. Conversely, MET copy number gain was a relatively common resistance mechanism in this patient group [39, 56]. Zheng et al. [44] analyzed CSF ctDNA through targeted sequencing in patients with anaplastic lymphoma kinase ( $A L K)$ rearranged NSCLC with LM, and ALK fusion was detected in $83.3 \%$ of the patients. ALK-resistant mutation was detected in one patient after resistance to alectinib. In addition to being capable of detecting a resistant mutation, serial CSF ctDNA analysis has the potential of longitudinally monitoring tumor burden in patients with LM [39, 44].

Different sequencing platforms may affect the mutation detection rate in patients with lung cancer. Studies have reported that droplet digital PCR (ddPCR) may have higher sensitivity in plasma EGFR mutation detection compared with amplification refractory mutation system PCR assays (ARMS) [57, 58]. However, few studies have directly compared different platforms for the CSF ctDNA analysis. Using the primary tumor testing results as reference, $\mathrm{Xu}$ et al. [40] reported that ddPCR and ARMS had similar sensitivity and specificity when used for CSF ctDNA analysis. Moreover, targeted sequencing with the NGS method exhibited a high mutation detection rate in CSF ctDNA (Table 2). In addition to sensitizing mutation,
NGS can be used to identify the resistance mechanism after targeted therapy.

The prognostic value of the CSF ctDNA analysis in patients with NSCLC with CNS metastasis has also been examined. Li et al. [53] identified five molecular subtypes by using cluster analysis and found that the cluster containing high percentages of CDK4, TP53, MET, and CDKN2A was associated with the worst prognosis. In patient with EGFR-mutant NSCLC with LM, the mutation type detected in CSF ctDNA indicated a different response to the thirdgeneration EGFR-TKI, osimertinib. Patients with EGFR exon 19 deletion had better intracranial progression-free survival compared to EGFR exon 21 p.L858R mutation. Moreover, the prognosis was better in patients harboring EGFR p.T790M mutation in CSF before osimeritnib use [50]. Thus, the ctDNA of CSF is a promising material for LM diagnosis, genomic alteration detection, and the treatment response supervision. The CSF ctDNA analysis should be considered a useful tool accompanied by cytological examination in patients with CNS metastasis, particularly in oncogene-addicted patients with LM.

\subsection{EVs and RNA}

Cells may communicate with each other through EVs, which comprise of proteins, genomic DNA, and various RNAs. EVs are divided into three groups based on their size and origin: exosomes, microvesicles, and apoptotic bodies [59]. Short noncoding RNAs regulate protein translation by binding to the 3' untranslated regions of messenger RNAs and are generally called microRNAs (miRNAs). In addition to being secreted by the cells in EVs, miRNAs could be released by necrotic cells as free oligonucleotides [60]. Recent studies have investigated the role of EVs and circulating miRNAs in CSF, in addition to CTCs and ctDNA, as a potential biomarker of CNS tumors.

Teplyuk et al. [61] analyzed the miRNAs of CSF by using quantitative reverse transcription PCR and observed that the levels of miR-10b and miR-21 were significantly higher in the CSF of patients with glioblastoma and metastatic brain tumors compared with those with nonneoplastic conditions. Furthermore, they found that the longitudinal miRNA profiles could reflect disease activity. Using microarray analysis and quantitative real-time PCR, Pan et al. [62] analyzed CSF miRNAs in patients with lung adenocarcinoma with LM. Three miRNAs in CSF (miR7975, miR7977, and miR7641) were significantly upregulated in patients with LM and the changes in these miRNAs correlated with disease course. Through function analysis, miR7977 was predicted to be involved in various pathways of cancer metastasis. In lung adenocarcinoma cells, miR7977 was found to be a key regulator of proliferation, migration, and invasion. However, some concerns regarding miRNA use in CSF exist. The major concern is specificity; differentiating identify the difference between cancer-derived and inflammation-derived miRNA profiles 
Table 2. Studies on ctDNA of CSF in patients with lung cancer with CNS metastasis.

\begin{tabular}{|c|c|c|c|c|c|c|}
\hline Study & Platform for sequencing & $\begin{array}{l}\text { Condition of patient } \\
\text { population }\end{array}$ & Number & Pattern of CNS metastasis & Mutation detection rate of CSF & Resistant mutation \\
\hline Swinkels et al., 2000 [36] & $\begin{array}{l}\text { Mutation-allele specific } \\
\text { amplification (PCR) }\end{array}$ & NSCLC & 2 & LM & $\begin{array}{c}\text { KRAS mutation } 100 \% \text { detected in CSF } \\
\qquad(2 / 2)\end{array}$ & NA \\
\hline Pentsova et al., 2016 [20] & Targeted sequencing & Solid tumors & 41, NSCLC:11 & $\begin{array}{c}32 \mathrm{BM} \\
9 \mathrm{LM}\end{array}$ & $\begin{array}{l}\text { 63\% (20/32) of patients with BM } \\
75 \%(3 / 4) \text { of patients with LM }\end{array}$ & EGFR p.T790M: 50\% (2/4) post-TKI \\
\hline Marchiò et al., 2017 [37] & Targeted sequencing & NSCLC & 2 & LM & $\begin{array}{c}\text { KRAS mutations } 100 \% \text { detected in CSF } \\
\qquad(2 / 2)\end{array}$ & NA \\
\hline Fan et al., 2018 [38] & Targeted sequencing & EGFR-mutant NSCLC & 11 & LM & $100 \%$ & EGFR p.T790M: 0\% \\
\hline Li et al., 2018 [39] & Targeted sequencing & EGFR-mutant NSCLC & 28 & LM & $100 \%$ & $\begin{array}{c}\text { EGFR p.T790M: } 30.4 \%(7 / 23) \\
\text { post-TKI } \\
\text { MET copy number gain:47.8\% (11/23) } \\
\text { post-TKI }\end{array}$ \\
\hline Xu et al., 2018 [40] & $\begin{array}{l}\text { Mutation-allele specific } \\
\text { amplification (PCR) }\end{array}$ & NSCLC & 49 & LM & $92.3 \%(39 / 42)$ in patients $E G F R$ mutation & $\begin{array}{l}\text { EGFR p.T790M: } 3.85 \%(1 / 26) \text { in } \\
\text { post-EGFR-TKI patients }\end{array}$ \\
\hline Ge et al., 2019 [41] & Targeted sequencing & NSCLC & 29 & LM & $66.67 \%$ overall & NA \\
\hline Huang et al., 2019 [51] & Droplet digital PCR & EGFR-mutant NSCLC & 35 & $\begin{array}{l}20 \mathrm{BM} \\
15 \mathrm{LM}\end{array}$ & $\begin{array}{l}50 \%(5 / 10) \text { of patients with BM } \\
75 \%(9 / 12) \text { of patients with LM }\end{array}$ & EGFR p.T790M: 13\% \\
\hline Zheng, et al., 2019 [44] & Targeted sequencing & ALK mutant NSCLC & 30 & LM & $\begin{array}{l}A L K \text { fusions were detected in } 83.3 \% \\
\text { (10/12) of samples }\end{array}$ & $\begin{array}{l}\text { ALK p.G1202R and p.C1156F were } \\
\text { found in one post-alectinib sample }\end{array}$ \\
\hline $\begin{array}{l}\text { Kawahara et al., } 2019 \\
\text { [52] }\end{array}$ & $\begin{array}{l}\text { Mutation-allele specific } \\
\text { amplification (PCR) }\end{array}$ & LC & 26 & NA & $\begin{array}{l}\text { 75\% of valid samples had } E G F R \\
\text { mutations }\end{array}$ & $\begin{array}{c}\text { EGFR p.T790M: } 33.3 \%(4 / 12) \text { in valid } \\
\text { samples }\end{array}$ \\
\hline Ying et al., 2019 [42] & Targeted sequencing & NSCLC & 92 & LM & $\begin{array}{l}\text { 81.5\% overall, EGFR is the most common } \\
\text { gene ( } 58 \%)\end{array}$ & EGFR p.T790M: 2.8\% (2/72) \\
\hline Zhao et al., 2019 [43] & Targeted sequencing & Malignancy & 35, LC:74\% & LM & $100 \%$ & EGFR p.T790M: 33.3\% (2/6) \\
\hline Ma et al., 2020 [45] & Targeted sequencing & NSCLC & 21 & $\begin{array}{l}10 \mathrm{BM} \\
11 \mathrm{LM}\end{array}$ & $\begin{array}{c}\text { 95.2\% (20/21) overall, } 100 \% \text { with LM } \\
\text { 81.8\% (9/11) LM patients had EGFR } \\
\text { mutation }\end{array}$ & NA \\
\hline Li, et al., 2020 [53] & Targeted sequencing & NSCLC & 94 & $\begin{array}{l}24 \mathrm{BM} \\
70 \mathrm{LM}\end{array}$ & $\begin{array}{l}100 \% \text { overall, } E G F R \text { is the most common } \\
\text { gene ( } 84 \%)\end{array}$ & NA \\
\hline Aldea et al., 2020 [17] & Targeted sequencing & NSCLC & 12 & $\begin{array}{c}1 \mathrm{BM} \\
11 \mathrm{LM}\end{array}$ & $83 \%$ & NA \\
\hline $\begin{array}{l}\text { Moushumi Suryavanshi } \\
\text { et al., } 2020 \text { [47] }\end{array}$ & droplet digital PCR & EGFR-mutant NSCLC & 17 & LM & $94.1 \%$ & $\begin{array}{l}\text { No EGFR p.T790M mutation was } \\
\text { found post-TKI }\end{array}$ \\
\hline
\end{tabular}


Table 2. Continued.

\begin{tabular}{|c|c|c|c|c|c|c|}
\hline Study & Platform for sequencing & $\begin{array}{l}\text { Condition of patient } \\
\text { population }\end{array}$ & Number & Pattern of CNS metastasis & Mutation detection rate of CSF & Resistant mutation \\
\hline Zhao et al., 2020 [46] & Targeted sequencing & Solid tumors & 58, LC: 42 & LM & $\begin{array}{c}100 \% \text { overall, EGFR mutation rate: } \\
70.97 \%\end{array}$ & NA \\
\hline Chiang et al., 2021 [48] & $\begin{array}{l}\text { Mutation-allele specific } \\
\text { amplification (PCR) }\end{array}$ & EGFR-mutant NSCLC & 48 & LM & $\begin{array}{l}68.8 \% \text { (33/48), } 80.5 \% \text { in patients with } \\
\text { abnormal cytologically finding }\end{array}$ & EGFR p.T790M: 14.6\% \\
\hline Choi et al., 2021 [49] & Nanowire-based cfDNA assay & $\begin{array}{l}\text { EGFR-mutant NSCLC } \\
\text { after third generation TKI }\end{array}$ & 11 & LM & $72.7 \%(8 / 11)$ & $\begin{array}{l}\text { EGFR p.C797S: } 36.3 \%(4 / 11) \\
\text { MET amplification: } 18.2 \%(2 / 11)\end{array}$ \\
\hline Zheng et al., 2021 [50] & Targeted sequencing & EGFR-mutant NSCLC & 80 & $\begin{array}{l}\text { LM } \\
\text { cohort 1: pre-osimertinib (45) } \\
\text { cohort 2: post-osimerinib (35) }\end{array}$ & $\begin{array}{l}\text { Cohort 1: 93.3\% (42/45) } \\
\text { Cohort 2: } 97.1 \%(34 / 35)\end{array}$ & $\begin{array}{c}\text { Cohort 1: } 21.4 \%(9 / 42) \\
\text { Cohort 2: } 21.7 \%(5 / 23) \text { maintained } \\
\text { EGFR p.T790M }\end{array}$ \\
\hline
\end{tabular}

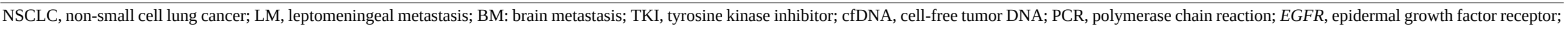
$A L K$, anaplastic lymphoma kinase. 


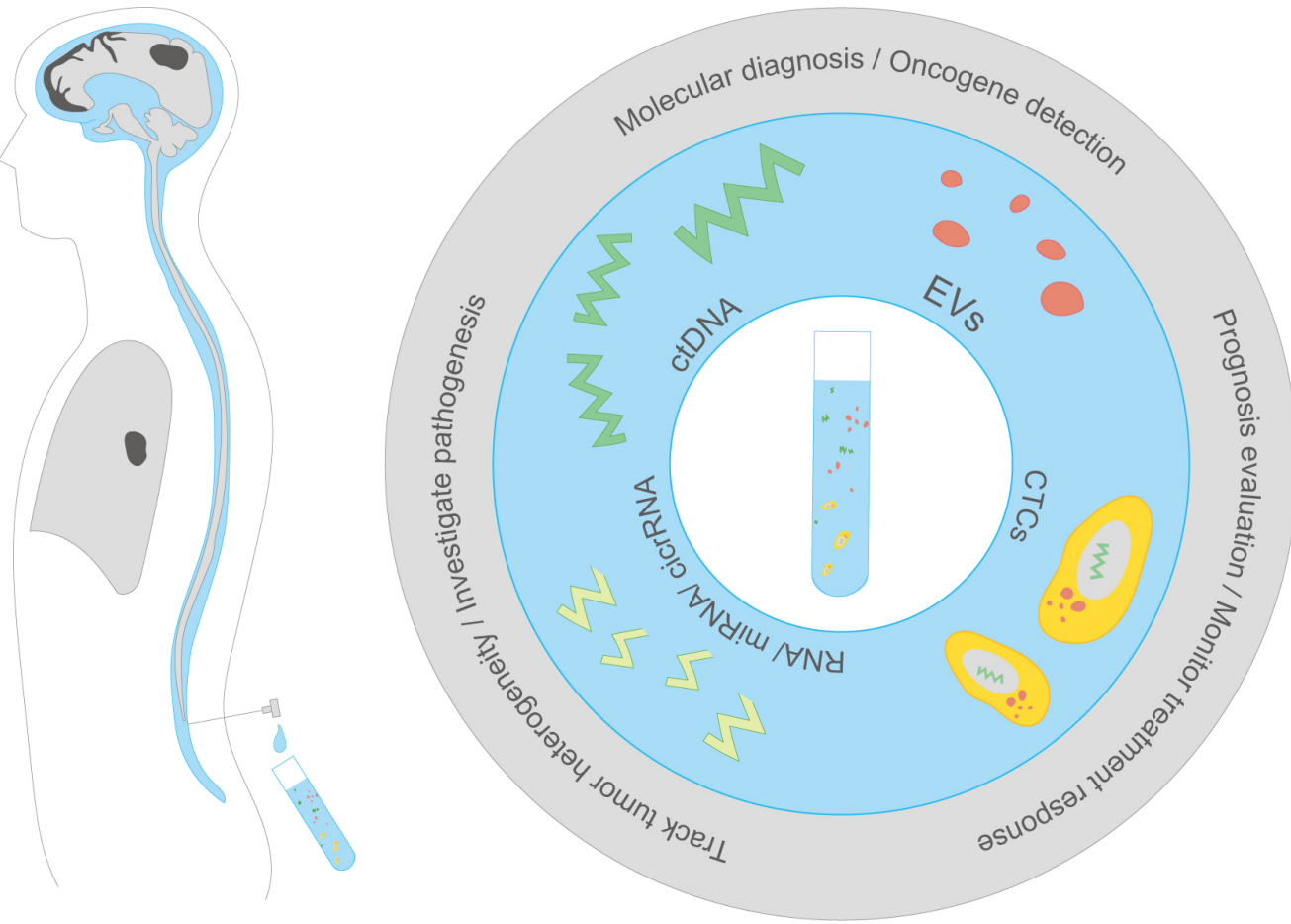

Fig. 1. Cerebrospinal fluid as a medium of liquid biopsy in non-small-cell lung cancer. miRNA, microRNA; circRNA, circular RNA; ctDNA, cell-free tumor DNA; EVs, extracellular vesicles; CTCs, circulating tumor cells.

is difficult. Furthermore, differentiating between miRNAs types in CSF, such as EV-associated miRNAs or naked miRNAs, is difficult. Additionally, a universal guideline is lacking for the processing of CSF samples, miRNA extraction, measurements, and data analysis [63].

Circular RNAs (circRNAs) are a class of noncoding RNAs that comprise a circular loop with miRNA binding sites and that regulate gene expression by acting as a miRNA sponge to compete with endogenous miRNAs [64]. Furthermore, circRNAs are abundant in the brain [65], and circRNA-miRNA networks that comprise circTTC39C and circ-PCCA have been identified in the CSF of patients with neurodegenerative diseases [66, 67]. Multiple circRNAs have been discovered in the blood and tumor tissue of patients with lung cancer [68,69]. The expression of CircRNA_102481 in exosomes was related to brain metastasis in patients with NSCLC [70]. Collectively, alterations in circRNAs can be detected in CSF and are currently being actively investigated for their potential as biomarkers for patients with lung cancer with CNS metastasis.

Lee et al. [71] measured nanoparticles in $472 \mathrm{CSF}$ samples and found that the concentration of CSF nanoparticles significantly increased in patients with LM. The concertation changes of nanoparticles were examined in $33 \mathrm{pa}-$ tients with NSCLC after intrathecal chemotherapy. EVs was positively correlated with overall survival. The same group further investigated the subpopulation of small noncoding RNA from EVs in patients with NSCLC with LM. The functions of these noncoding RNA, particularly miR21, in LM pathogenesis were documented [72]. Further studies are required to investigate the role of EVs as a novel pharmacological target for LM.

\section{Summary and perspective}

The use of CSF as a medium of liquid biopsy in patients with NSCLC with CNS metastasis is still evolving. In addition to having better diagnostic sensitivity, CTCs detection in CSF can provide information regarding tumor burden, particularly in patients with LM. The analysis of CSF ctDNA could identify driver oncogenes, monitor treatment response, and track the resistance mechanism [73]. The sequencing of RNA or EVs in CSF is new in this field and may lead to a better understanding of LM pathogenesis (Fig. 1). No study has compared these platforms with respect to detection rate and clinical usefulness. However, we believe that each platform could provide complementary information. The optimal use of these materials in CSF for diagnosis, tumor heterogenicity tracking and treatment guidance requires prospective studies for validation. It is hoped that the application of liquid biopsy by using CSF in clinical practice will improve outcomes in this patient group. 


\section{Author contributions}

CLC and CHC designed the study. HCH performed the illustration. CLC and YHL wrote the manuscript. All authors contributed to editorial changes in the manuscript. All authors read and approved the final manuscript.

\section{Ethics approval and consent to participate}

Not applicable.

\section{Acknowledgment}

This manuscript was edited by Wallace Academic Editing.

\section{Funding}

This study was funded by Taipei Veterans General Hospital, Taiwan (V110B-008).

\section{Conflict of interest}

CLC and CHC has received honoraria from AstraZeneca, Boehringer Ingelheim, Pfizer, and Roche. Other authors declare no conflict of interest.

\section{References}

[1] Jamal-Hanjani M, Spicer J. Epidermal Growth Factor Receptor Tyrosine Kinase Inhibitors in the Treatment of Epidermal Growth Factor Receptor-Mutant Non-Small Cell Lung Cancer Metastatic to the Brain. Clinical Cancer Research. 2012; 18: 938-944.

[2] Rangachari D, Yamaguchi N, VanderLaan PA, Folch E, Mahadevan A, Floyd SR, et al. Brain metastases in patients with EGFR -mutated or ALK -rearranged non-small-cell lung cancers. Lung Cancer. 2015; 88: 108-111.

[3] Heon S, Yeap BY, Britt GJ, Costa DB, Rabin MS, Jackman DM, et al. Development of Central Nervous System Metastases in $\mathrm{Pa}$ tients with Advanced Non-Small Cell Lung Cancer and Somatic EGFR Mutations Treated with Gefitinib or Erlotinib. Clinical Cancer Research. 2010; 16: 5873-5882.

[4] Han G, Bi J, Tan W, Wei X, Wang X, Ying X, et al. A retrospective analysis in patients with EGFR-mutant lung adenocarcinoma: is EGFR mutation associated with a higher incidence of brain metastasis? Oncotarget. 2016; 7: 56998-57010.

[5] Wang H, Wang Z, Zhang G, Zhang M, Zhang X, Li H, et al. Driver genes as predictive indicators of brain metastasis in patients with advanced NSCLC: EGFR, ALK, and RET gene mutations. Cancer Medicine. 2020; 9: 487-495.

[6] Sacher AG, Jänne PA, Oxnard GR. Management of acquired resistance to epidermal growth factor receptor kinase inhibitors in patients with advanced non-small cell lung cancer. Cancer. 2014; 120: 2289-2298.

[7] Jiang T, Fang Z, Tang S, Cheng R, Li Y, Ren S, et al. Mutational Landscape and Evolutionary Pattern of Liver and Brain Metastasis in Lung Adenocarcinoma. Journal of Thoracic Oncology. 2021; 16: 237-249.
[8] Kang Y, Jin Y, Li Q, Yuan X. Advances in Lung Cancer Driver Genes Associated with Brain Metastasis. Frontiers in Oncology. 2021; 10: 606300 .

[9] Mack F, Baumert BG, Schäfer N, Hattingen E, Scheffler B, Herrlinger $\mathrm{U}$, et al. Therapy of leptomeningeal metastasis in solid tumors. Cancer Treatment Reviews. 2016; 43: 83-91.

[10] Li Y, Jiang B, Yang J, Tu H, Zhou Q, Guo W, et al. Leptomeningeal Metastases in Patients with NSCLC with EGFR Mutations. Journal of Thoracic Oncology. 2017; 11: 1962 1969.

[11] Remon J, Le Rhun E, Besse B. Leptomeningeal carcinomatosis in non-small cell lung cancer patients: a continuing challenge in the personalized treatment era. Cancer Treatment Reviews. 2017; 53: 128-137.

[12] Cheng H, Perez-Soler R. Leptomeningeal metastases in nonsmall-cell lung cancer. The Lancet. Oncology. 2018; 19: e43e55.

[13] Le Rhun E, Weller M, Brandsma D, Van den Bent M, de Azambuja E, Henriksson R, et al. EANO-ESMO Clinical Practice Guidelines for diagnosis, treatment and follow-up of patients with leptomeningeal metastasis from solid tumours. Annals of Oncology. 2018; 28: iv84-iv99.

[14] Le Rhun E, Devos P, Boulanger T, Smits M, Brandsma D, Rudà $\mathrm{R}$, et al. The RANO Leptomeningeal Metastasis Group proposal to assess response to treatment: lack of feasibility and clinical utility and a revised proposal. Neuro-Oncology. 2019; 21: 648658.

[15] Goldman JW, Noor ZS, Remon J, Besse B, Rosenfeld N. Are liquid biopsies a surrogate for tissue EGFR testing? Annals of Oncology. 2019; 29: i38-i46.

[16] De Mattos-Arruda L, Mayor R, Ng CKY, Weigelt B, MartínezRicarte F, Torrejon D, et al. Cerebrospinal fluid-derived circulating tumour DNA better represents the genomic alterations of brain tumours than plasma. Nature Communications. 2016; 6 : 8839.

[17] Aldea M, Hendriks L, Mezquita L, Jovelet C, Planchard D, Auclin E, et al. Circulating Tumor DNA Analysis for Patients with Oncogene-Addicted NSCLC with Isolated Central Nervous System Progression. Journal of Thoracic Oncology. 2020; 15: 383391.

[18] Boire A, Brandsma D, Brastianos PK, Le Rhun E, Ahluwalia M, Junck L, et al. Liquid biopsy in central nervous system metastases: a RANO review and proposals for clinical applications. Neuro-Oncology. 2019; 21: 571-584.

[19] Iliff JJ, Wang M, Liao Y, Plogg BA, Peng W, Gundersen GA, et al. A paravascular pathway facilitates CSF flow through the brain parenchyma and the clearance of interstitial solutes, including amyloid $\beta$. Science Translational Medicine. 2013; 4 : 147 ra111.

[20] Pentsova EI, Shah RH, Tang J, Boire A, You D, Briggs S, et al. Evaluating Cancer of the Central Nervous System through next-Generation Sequencing of Cerebrospinal Fluid. Journal of Clinical Oncology. 2017; 34: 2404-2415.

[21] Wasserstrom WR, Glass JP, Posner JB. Diagnosis and treatment of leptomeningeal metastases from solid tumors: Experience with 90 patients. Cancer. 1982; 49: 759-772.

[22] Glantz MJ, Cole BF, Glantz LK, Cobb J, Mills P, Lekos A, et al. Cerebrospinal fluid cytology in patients with cancer: minimizing false-negative results. Cancer. 1998; 82: 733-739.

[23] Subirá D, Serrano C, Castañón S, Gonzalo R, Illán J, Pardo J, et al. Role of flow cytometry immunophenotyping in the diagnosis of leptomeningeal carcinomatosis. Neuro-Oncology. 2012; 14: 43-52.

[24] Nayak L, Fleisher M, Gonzalez-Espinoza R, Lin O, Panageas K, Reiner A, et al. Rare cell capture technology for the diagnosis of leptomeningeal metastasis in solid tumors. Neurology. 2013; 80: 1598-605; discussion 1603.

[25] Subirá D, Simó M, Illán J, Serrano C, Castañón S, Gonzalo R, et al. Diagnostic and prognostic significance of flow cytometry im- 
munophenotyping in patients with leptomeningeal carcinomatosis. Clinical \& Experimental Metastasis. 2015; 32: 383-391.

[26] Tu Q, Wu X, Le Rhun E, Blonski M, Wittwer B, Taillandier L, et al. CellSearch technology applied to the detection and quantification of tumor cells in CSF of patients with lung cancer leptomeningeal metastasis. Lung Cancer. 2016; 90: 352-357.

[27] Milojkovic Kerklaan B, Pluim D, Bol M, Hofland I, Westerga J, van Tinteren $\mathrm{H}$, et al. EpCAM-based flow cytometry in cerebrospinal fluid greatly improves diagnostic accuracy of leptomeningeal metastases from epithelial tumors. NeuroOncology. 2017; 18: 855-862.

[28] Jiang B, Li Y, Guo W, Zhang X, Chen Z, Su J, et al. Detection of Driver and Resistance Mutations in Leptomeningeal Metastases of NSCLC by next-Generation Sequencing of Cerebrospinal Fluid Circulating Tumor Cells. Clinical Cancer Research. 2018; 23: 5480-5488.

[29] Lin X, Fleisher M, Rosenblum M, Lin O, Boire A, Briggs S, et al. Cerebrospinal fluid circulating tumor cells: a novel tool to diagnose leptomeningeal metastases from epithelial tumors. Neuro-Oncology. 2018; 19: 1248-1254.

[30] Torre M, Lee EQ, Chukwueke UN, Nayak L, Cibas ES, Lowe AC. Integration of rare cell capture technology into cytologic evaluation of cerebrospinal fluid specimens from patients with solid tumors and suspected leptomeningeal metastasis. Journal of the American Society of Cytopathology. 2020; 9: 45-54.

[31] van Bussel MTJ, Pluim D, Milojkovic Kerklaan B, Bol M, Sikorska K, Linders DTC, et al. Circulating epithelial tumor cell analysis in CSF in patients with leptomeningeal metastases. Neurology. 2020; 94: e521-e528.

[32] Nevel KS, DiStefano N, Lin X, Skakodub A, Ogilvie SQ, Reiner AS, et al. A retrospective, quantitative assessment of disease burden in patients with leptomeningeal metastases from nonsmall-cell lung cancer. Neuro-Oncology. 2020; 22: 675-683.

[33] Lv Y, Mu N, Ma C, Jiang R, Wu Q, Li J, et al. Detection value of tumor cells in cerebrospinal fluid in the diagnosis of meningeal metastasis from lung cancer by immuno-FISH technology. Oncology Letters. 2019; 12: 5080-5084.

[34] Hyun K, Koo G, Han H, Sohn J, Choi W, Kim S, et al. Epithelialto-mesenchymal transition leads to loss of EpCAM and different physical properties in circulating tumor cells from metastatic breast cancer. Oncotarget. 2017; 7: 24677-24687.

[35] Ruan H, Zhou Y, Shen J, Zhai Y, Xu Y, Pi L, et al. Circulating tumor cell characterization of lung cancer brain metastases in the cerebrospinal fluid through single-cell transcriptome analysis. Clinical and Translational Medicine. 2020; 10: e246.

[36] Swinkels DW, de Kok JB, Hanselaar A, Lamers K, Boerman RH. Early detection of leptomeningeal metastasis by PCR examination of tumor-derived K-ras DNA in cerebrospinal fluid. Clinical Chemistry. 2000; 46: 132-133.

[37] Marchiò C, Mariani S, Bertero L, Di Bello C, Francia Di Celle P, Papotti M, et al. Liquoral liquid biopsy in neoplastic meningitis enables molecular diagnosis and mutation tracking: a proof of concept. Neuro-Oncology. 2019; 19: 451-453.

[38] Fan Y, Zhu X, Xu Y, Lu X, Xu Y, Wang M, et al. CellCycle and DNA-Damage Response Pathway is Involved in Leptomeningeal Metastasis of Non-Small Cell Lung Cancer. Clinical Cancer Research. 2019; 24: 209-216.

[39] Li YS, Jiang BY, Yang JJ, Zhang XC, Zhang Z, Ye JY, et al. Unique genetic profiles from cerebrospinal fluid cell-free DNA in leptomeningeal metastases of EGFR-mutant non-small-cell lung cancer: a new medium of liquid biopsy. Annals of Oncology. 2018; 29: 945-952.

[40] Xu Y, Hu M, Zhang M, Zhong W, Yin X, Sun Y, et al. Prospective study revealed prognostic significance of responses in leptomeningeal metastasis and clinical value of cerebrospinal fluidbased liquid biopsy. Lung Cancer. 2019; 125: 142-149.

[41] Ge M, Zhan Q, Zhang Z, Ji X, Zhou X, Huang R, et al. Different next-generation sequencing pipelines based detection of tumor DNA in cerebrospinal fluid of lung adenocarcinoma cancer pa- tients with leptomeningeal metastases. BioMed Central Cancer 2019; 19: 143

[42] Ying S, Ke H, Ding Y, Liu Y, Tang X, Yang D, et al. Unique genomic profiles obtained from cerebrospinal fluid cell-free DNA of non-small cell lung cancer patients with leptomeningeal metastases. Cancer Biology \& Therapy. 2019; 20: 562-570.

[43] Zhao Y, He J, Zou Y, Guo X, Cui J, Guo L, et al. Evaluating the cerebrospinal fluid ctDNA detection by next-generation sequencing in the diagnosis of meningeal Carcinomatosis. BioMed Central Neurology. 2019; 19: 331.

[44] Zheng M, Li Y, Jiang B, Tu H, Tang W, Yang J, et al. Clinical Utility of Cerebrospinal Fluid Cell-Free DNA as Liquid Biopsy for Leptomeningeal Metastases in ALK-Rearranged NSCLC. Journal of Thoracic Oncology. 2019; 14: 924-932.

[45] Ma C, Yang X, Xing W, Yu H, Si T, Guo Z. Detection of circulating tumor DNA from non-small cell lung cancer brain metastasis in cerebrospinal fluid samples. Thoracic Cancer. 2020; 11: 588-593.

[46] Zhao Y, He JY, Cui JZ, Meng ZQ, Zou YL, Guo XS, et al. Detection of genes mutations in cerebrospinal fluid circulating tumor DNA from neoplastic meningitis patients using next generation sequencing. BioMed Central Cancer. 2020; 20: 690.

[47] Suryavanshi M, Jaipuria J, Panigrahi MK, Goyal N, Singal R, Mehta A, et al. CSF cell-free DNA EGFR testing using DdPCR holds promise over conventional modalities for diagnosing leptomeningeal involvement in patients with non-small cell lung cancer. Lung Cancer. 2020; 148: 33-39.

[48] Chiang C, Lee C, Huang H, Wu C, Yeh Y, Shen C, et al. Utility of Cerebrospinal Fluid Cell-Free DNA in Patients with EGFRMutant Non-Small-Cell Lung Cancer with Leptomeningeal Metastasis. Targeted Oncology. 2021; 16: 207-214.

[49] Choi W, Cho Y, Park S, Hwang KH, Han J, Lee Y. A nanowirebased liquid biopsy method using cerebrospinal fluid cell-free DNA for targeted management of leptomeningeal carcinomatosis. Journal of Cancer Research and Clinical Oncology. 2021; 147: 213-222.

[50] Zheng M, Li Y, Tu H, Jiang B, Yang J, Zhou Q, et al. Genotyping of Cerebrospinal Fluid Associated with Osimertinib Response and Resistance for Leptomeningeal Metastases in EGFRMutated NSCLC. Journal of Thoracic Oncology. 2021; 16: 250258.

[51] Huang R, Xu X, Li D, Chen K, Zhan Q, Ge M, et al. Digital PCRBased Detection of EGFR Mutations in Paired Plasma and CSF Samples of Lung Adenocarcinoma Patients with Central Nervous System Metastases. Targeted Oncology. 2019; 14: 343350 .

[52] Kawahara A, Abe H, Murata K, Ishii H, Azuma K, Takase Y, et al. Screening system for epidermal growth factor receptor mutation detection in cytology cell-freeDNAof cerebrospinal fluid based on assured sample quality. Cytopathology. 2019; 30: 144149.

[53] Li Y, Zheng M, Jiang B, Tu H, Yang J, Zhang X, et al. Association of Cerebrospinal Fluid Tumor DNA Genotyping with Survival among Patients with Lung Adenocarcinoma and Central Nervous System Metastases. JAMA Network Open. 2020; 3: e209077.

[54] John T, Akamatsu H, Delmonte A, Su W, Lee JS, Chang G, et al. EGFR mutation analysis for prospective patient selection in AURA3 phase III trial of osimertinib versus platinumpemetrexed in patients with EGFR T790M-positive advanced non-small-cell lung cancer. Lung Cancer. 2019; 126: 133-138.

[55] Jenkins S, Yang JC, Jänne PA, Thress KS, Yu K, Hodge R, et al. EGFR Mutation Analysis for Prospective Patient Selection in Two Phase II Registration Studies of Osimertinib. Journal of Thoracic Oncology. 2018; 12: 1247-1256.

[56] Nanjo S, Arai S, Wang W, Takeuchi S, Yamada T, Hata A, et al. MET Copy Number Gain is Associated with Gefitinib Resistance in Leptomeningeal Carcinomatosis of EGFR-mutant Lung Cancer. Molecular Cancer Therapeutics. 2017; 16: 506-515. 
[57] Jiang X, Liu W, Zhu X, Xu X. Evaluation of EGFR mutations in NSCLC with highly sensitive droplet digital PCR assays. Molecular Medicine Reports. 2019; 20: 593-603.

[58] Li C, He Q, Liang H, Cheng B, Li J, Xiong S, et al. Diagnostic Accuracy of Droplet Digital PCR and Amplification Refractory Mutation System PCR for Detecting EGFR Mutation in CellFree DNA of Lung Cancer: A Meta-Analysis. Frontiers in Oncology 2020; 10: 290.

[59] Chung I, Rajakumar G, Venkidasamy B, Subramanian U, Thiruvengadam M. Exosomes: Current use and future applications. Clinica Chimica Acta. 2020; 500: 226-232.

[60] Kopkova A, Sana J, Fadrus P, Slaby O. Cerebrospinal fluid microRNAs as diagnostic biomarkers in brain tumors. Clinical Chemistry and Laboratory Medicine. 2019; 56: 869-879.

[61] Teplyuk NM, Mollenhauer B, Gabriely G, Giese A, Kim E, Smolsky M, et al. MicroRNAs in cerebrospinal fluid identify glioblastoma and metastatic brain cancers and reflect disease activity. Neuro-Oncology. 2012; 14: 689-700.

[62] Pan Z, Yang G, He H, Gao P, Jiang T, Chen Y, Zhao G. Identification of Cerebrospinal Fluid MicroRNAs Associated with Leptomeningeal Metastasis from Lung Adenocarcinoma. Frontiers in Oncology. 2020; 10: 387.

[63] Shalaby T, Grotzer MA. Tumor-Associated CSF MicroRNAs for the Prediction and Evaluation of CNS Malignancies. International Journal of Molecular Sciences. 2016; 16: 29103-29119.

[64] Su M, Xiao Y, Ma J, Tang Y, Tian B, Zhang Y, et al. Circular RNAs in Cancer: emerging functions in hallmarks, stemness, resistance and roles as potential biomarkers. Molecular Cancer. 2019; 18: 90.

[65] Zhang Z, Yang T, Xiao J. Circular RNAs: Promising Biomarkers for Human Diseases. EBioMedicine. 2018; 34: 267-274.

[66] Li Y, Fan H, Sun J, Ni M, Zhang L, Chen C, et al. Circular RNA expression profile of Alzheimer's disease and its clinical significance as biomarkers for the disease risk and progression. The International Journal of Biochemistry \& Cell Biology. 2020; 123: 105747.

[67] Moreno-García L, López-Royo T, Calvo AC, Toivonen JM, de la Torre M, Moreno-Martínez L, Molina N, et al. Competing Endogenous RNA Networks as Biomarkers in Neurodegenerative Diseases. International Journal of Molecular Sciences. 2020; 21: 95820.

[68] Ishola AA, La'ah AS, Le HD, Nguyen VQ, Yang Y, Chou S, et al. Non-coding RNA and lung cancer progression. Journal of the Chinese Medical Association. 2020; 83: 8-14.
[69] Luo YH, Yang YP, Chien CS, Yarmishyn AA, Ishola AA, Chien Y, et al. Plasma Level of Circular RNA hsa_circ_0000190 Correlates with Tumor Progression and Poor Treatment Response in Advanced Lung Cancers. Cancers. 2020; 12: 1740.

[70] Yang B, Teng F, Chang L, Wang J, Liu D, Cui Y, et al. Tumorderived exosomal circRNA_102481 contributes to EGFR-TKIs resistance via the miR-30a-5pROR1 axis in non-small cell lung cancer. Aging. 2021; 13: 13264-13286.

[71] Lee KY, Im JH, Lin W, Gwak HS, Kim JH, Yoo BC, et al. Nanoparticles in 472 Human Cerebrospinal Fluid: Changes in Extracellular Vesicle Concentration and miR-21 Expression as a Biomarker for Leptomeningeal Metastasis. Cancers. 2020; 12: 2745.

[72] Lee KY, Seo Y, Im JH, Rhim J, Baek W, Kim S, et al. Molecular Signature of Extracellular Vesicular Small Non-Coding RNAs Derived from Cerebrospinal Fluid of Leptomeningeal Metastasis Patients: Functional Implication of miR-21 and Other Small RNAs in Cancer Malignancy. Cancers. 2021; 13: 209.

[73] Pellerino A, Brastianos PK, Rudà R, Soffietti R. Leptomeningeal Metastases from Solid Tumors: Recent Advances in Diagnosis and Molecular Approaches. Cancers. 2021; 13: 2888.

Abbreviations: NSCLC, non-mall-cell lung cancer; CNS, central nervous system; EGFR, epidermal growth factor receptor; CSF, Cerebrospinal fluid; LM, Leptomeningeal metastasis; CTC, circulating tumor cells; EpCAM, epithelial cell adhesion molecule; ctDNA, cell-free tumor DNA; ALK, anaplastic lymphoma kinase; EV, extracellular vesicles; NGS, next-generation sequencing.

Keywords: Non-small-cell lung cancer; Cerebrospinal fluid; Liquid biopsy; Cell free tumor DNA

Send correspondence to: Chao-Hua Chiu, Department of Chest Medicine, Taipei Veterans General Hospital, 112 Taipei, Taiwan, School of Medicine, National Yang Ming Chiao Tung University, 112 Taipei, Taiwan, E-mail: jhchiou@vghtpe.gov.tw 